\title{
PENGARUH TERAPI MUSIK DZIKIR TERHADAP TINGKAT DEPRESI PADA LANSIA DI RT 3 RW 2 RUMAH DINAS TNI-AL PULUNGAN
}

\author{
Farida Umamah, Annisa Fabiyanti \\ (Universitas Nahdlatul Ulama Surabaya, Jl. SMEA no. 57 Surabaya) \\ umamahfarida@unusa.ac.id
}

\begin{abstract}
The effects of aging process experienced by the elderly cause various physical, mental, and socio-economic problems. One of the psychological problems experienced by them is depression. Hence, this study was purposed to find out the effect of dhikr music therapy on the depression level in the elderly living in the naval official housing complex RT 3 RW 2 Pulungan. This pre-experimental study was done by using a one-group pretest-posttest design, involving the population totaling 30 people. 28 elderly people aged 60-74 years were taken as the samples by using probability sampling, namely simple random sampling technique. The independent variable was the dhikr music therapy, whereas the dependent variable was the depression level in the elderly. The instrument used in this study was DASS 42 (Depression Anxiety Stress Scale) implemented to the elderly, then analyzed by using Wilcoxon signed-rank test. The result of this study showed that of 28 respondents before receiving dhikr music therapy, most of them $(57.1 \%)$ had severe depression After receiving the therapy, half of them (50.0\%) had mild depression. The result of analysis showed that $\rho=0.000$ in which $\rho<0.05$ so that $\mathrm{H}_{0}$ was rejected. It illustrated that there was an effect of dhikr music therapy on the depression level in the elderly living in the naval official housing complex RT 3 RW 2 Pulungan. In conclusion, dhikr music therapy is effective to decrease the level of depression experienced by the elderly. Therefore, the nurses are expected to continue the activity of dhikr music therapy in the above-mentioned location of this study so that the elderly people get a motivation to do it routinely in group.
\end{abstract}

Key words: dhikr music teraphy, depression, elderly

Abstrak: Pengaruh proses penuaan yang dialami oleh lansia menimbulkan berbagai masalah baik secara fisik, mental, maupun sosial ekonomi. Salah satu masalah psikologis yang dialami lansia adalah terjadinya depresi.Tujuan dari penelitian ini adalah untuk mengetahui pengaruh terapi musik dzikir terhadap tingkat depresi pada lansia di RT 3 RW 2 RumahDinas TNI-AL Pulungan.Penelitian ini menggunakan desain pre-eksperimental dengan pendekatan one group pra-post test design, menggunakan populasi 30 responden dengan besar sampel 28 lansia yang berusia 60 74 tahun, menggunakan probability sampling dengan teknik simple random sampling. Variabel independen adalah terapi musik dzikir dan variabel dependen adalah tingkat depresi pada lansia. Instrumen yang digunakan adalahDASS 42 (Depression Anxiety Stress Scale)dan diberikan kepada responden lanisa, dan dianalisis menggunakan uji Wilcoxon sign test.Hasil penelitian menunjukkan dari 28 responden sebelum diberikan terapi musik dzikir sebagian besar $(57,1 \%)$ mengalami 
depresi berat dan setelah diberikan terapi musik dzikir didapatkan setengah dari responden $(50,0 \%)$ mengalami depresi ringan. Hasil analisis $\rho=0,000$ dimana $\rho<0,05$ berarti $\mathrm{H}_{0}$ ditolak artinya ada pengaruh terapi musik dzikir terhadap tingkat depresi pada lansia di RT 3 RW 2 Rumah Dinas TNI-AL Pulungan.Simpulan dari penelitian ini bahwa terapi musik dzikir mampu menurunkan tingkat depresi pada lansia. Diharapkan perawat bisa melanjutkan kegiatan terapi musik dzikir di RT 3 RW 2 Rumah Dinas TNI-AL Pulungan, sehingga lansia termotivasi untuk melakukan hal ini secara rutin dan berkelompok.

Kata Kunci : Terapi Musik Dzikir, Tingkat Depresi, Lansia

\section{PENDAHULUAN}

Proses penuaan merupakan alamiah, yang berarti seseorang telah melalui tiga tahap kehidupan yaitu anak, dewasa dan tua. Tiga tahap ini berbeda, baik secara biologis, maupun psikologis. Salah satu masalah proses psikologis yang terjadi pada tahap tua adalah depresi. Depresi adalah suatu perasaan sedih yang sangat mendalam yang terjadi setelah mengalami suatu peristiwa dramatis atau menyedihkan, misalnya kehilangan seseorang yang disayangi. Seseorang bisa jatuh dalam kondisi depresi jika ia terus - menerus memikirkan kejadian pahit, menyakitkan, keterpurukan dan peristiwa sedih yang menimpa dalam waktu lama melebihi waktu normal bagi kebanyakan orang (Junaidi, 2012). Fenomena ini jelas mendatangkan sejumlah konsekuensi, antara lain timbulnya masalah fisik, mental, sosial, serta kebutuhan pelayanan kesehatan (Nugroho, 2008).

Berdasarkan survey awal yang dilakukan peneliti pada bulan Januari 2017 di RT 3 RW 2 Rumah Dinas TNI-AL Pulungan melalui wawancara kepada 10 orang lansia, didapat 6 dari 10 orang menyatakan lebih suka menyendiri dari pada berkumpul dengan teman sebayanya, lansia juga menyatakan terkadang murung atau marah dengan apa yang akan terjadi dikemudian hari. Sedangkan 4 orang lansia menyatakan senang dan bisa menerima kenyataan yang ada dan masih bisa masak dan membantu keluarganya serta tidak ada masalah yang dikhawatirkan.

Adanya konflik keluarga serta kondisi lingkungan yang buruk dan berkurangnya interaksi sosial dengan orang yang dicintai juga bisa menjadi pemicu depresi pada lansia. Depresi dapat menimbulkan dampak negatif misalnya: perasaan tidak berguna, mudah marah, sedih, merasa disingkirkan dan tidak dibutuhkan lagi. Selain itu, stres juga dapat menyebabkan seseorang menjadi lebih sensitif atau peka terhadap depresi (Haryadi, 2012).

Depresi dapat menimbulkan dampak negatif misalnya: perasaan tidak berguna, mudah marah, sedih, merasa disingkirkan dan tidak dibutuhkan lagi. Selain itu, stres juga dapat menyebabkan seseorang menjadi lebih sensitif atau peka terhadap depresi (Haryadi, 2012).

Adapun upaya penanganan secara farmakologis dapat diatasi dengan menggunakan obat-obatan analgesik. Sedangkan penatalaksanaan non farmokologis terhadap depresi dapat dilakukan dengan berbagai cara, meliputi pendekatan psikodinamik, psiko internal, terapi perilaku, terapi humanistik-eksistensial, terapi kognitif 
Beck dan terapi musik dzikir. Terapi musik dzikir digunakan sebagai salah satu terapi pengobatan. Musik dzikir dapat mendatangkan ketenangan bisa jadi terapi yang dapat diartikan sebagai pengobatan. Musik dzikir memiliki aspek terapeutik, sehingga dzikir digunakan untuk penyembuhan, menenangkan, dan memperbaiki kondisi fisik dan fisiologis lansia. Hal ini dikarenakan doa dan dzikir mengandung unsur spiritual yang dapat membangkitkan harapan (hope) dan rasa percaya diri (self confidence) pada diri seseorang yang sedang sakit sehingga kekebalan tubuh serta proses penyembuhan dapat meningkat. Berdasarkan penelitian Nurhadi dan Nursalam (2003), bimbingan spiritual berdampak positif terhadap pengurangan stres klien yang dirawat di rumah sakit dan klien dengan penyakit terminal, jika stres dapat dikurangi maka respon imun akan meningkat sehingga infeksi-infeksi sekunder dapat diminimalkan (Setyoadi, 2011). Respon tahap awal tubuh HPA (Hipotalamic Pituitary Adrenal) memegang peranan penting dalam beradaptasi terhadap stres eksternalmaupun internal dan pada keadaan depresi terjadi peningkatan aktivitas HPA yang ditandai dengan pelepasan $\mathrm{CRH}$ (Corticotropin Releasing Hormone) dari hipotalamus. CRH banyak ditemukan di PVN (Paraventricular Nucleus) hipotalamus. Kemudian pelepasan $\mathrm{CRH}$ dari hipotalamus dirangsang oleh noradrogenik, serotonergik dan kolinergik yang menyebabkan terjadinya depresi. Peningkatan rangsangan terhadap hipofisis anterior menyebabkan skresi ACTH (Adreno Cortico Tropin Hormone). ACTH berperan merangsang keluarnya kortisol dari korteks adrenal. Peningkatan ACTH pada keadaan depresi yang berlangsung lama dapat menimbulkan hiperaktivitas kelenjar adrenal dan kortisol setelah itu, yang dikeluarkan dari kelenjar adrenal lalu masuk dalam sirkulasi umum, dimana pada pasien depresi terjadi peningkatan kadar kortisol terutama pada sore dan malam hari. Sehingga penting untuk mempertahankan kondisi mental, fisik seseorang (Nurmiati, 2005). Tujuan dalam penelitian ini adalah mengindentifikasi tingkat depresi sebelum dilakukan terapi musik dzikir dan sesudah dilakukan terapi musik dzikir serta menganalisis pengaruh terapi musik dzikir terhadap tingkat depresi pada lansia.

\section{METODE PENELITIAN}

Penelitian ini menggunakan penelitian penelitian pre eksperimental yaitu one-group pra-post test, Populasi penelitian ini adalah seluruh lansia yang berusia 60-74 tahun di RT 3 RW 2 Rumah Dinas TNI-AL Pulungan sebesar 30 orang dengan besar sampel 28 responden yang diambil melalui probability sampling dengan teknik simple random sampling. Instrumen penelitian ini menggunakan lembar kuesioner. Analisis data menggunakan uji wilcoxon signed rank test apabila $\rho$ $<\alpha$ maka $\mathrm{H}_{\mathrm{o}}$ ditolak berarti ada pengaruh terapi musik dzikir terhadap tingkat depresi pada lansia di RT 3 RW 2 Rumah Dinas TNI-AL Pulungan.

\section{HASIL \& PEMBAHASAN \\ Hasil}

1. Data Umum

a. Karakteristik responde berdasarkan jenis kelamin.

Tabel 5.1 Distribusi frekuensi responden berdasarkan jenis kelamin di RT 3 RW 2 
Rumah Dinas TNI-AL Pulungan 2017.

\begin{tabular}{|c|c|c|c|}
\hline $\begin{array}{l}\mathrm{N} \\
\mathrm{O}\end{array}$ & $\begin{array}{l}\text { Jenis } \\
\text { Kelamin }\end{array}$ & $\begin{array}{l}\text { Frekuen } \\
\text { si }\end{array}$ & $\begin{array}{l}\text { Persentas } \\
\text { e }(\%)\end{array}$ \\
\hline 1 & Laki-laki & 12 & $42,9 \%$ \\
\hline 2 & $\begin{array}{l}\text { Perempua } \\
\mathrm{n}\end{array}$ & 16 & $57,1 \%$ \\
\hline Ju1 & $\mathrm{a}$ & 28 & $100 \%$ \\
\hline
\end{tabular}

Sumber : Data Primer, Agustus 2017

Berdasarkan tabel 5.1 menunjukkan dari 28 responden sebagain besar 16 responden $(57,1 \%)$ berjenis kelamin perempuan.

2. Data Khusus

a. Karakteristik tingkat depresi pada lansia sebelum diberikan terapi musik dzikir.

Tabel 5.3 Distribusi frekuensi responden berdasarkan tingkat depresi pada lansia sebelum diberikan terapi musik dzikir di RT 3 RW 2 Rumah Dinas TNI-AL Pulungan 2017.

\begin{tabular}{llll}
\hline $\mathrm{N}$ & $\begin{array}{l}\text { Tingkat } \\
\text { o } \\
\text { Depresi } \\
\text { Pre }\end{array}$ & $\begin{array}{l}\text { Frekuensi } \\
(\mathrm{n})\end{array}$ & $\begin{array}{l}\text { Persentase } \\
(\%)\end{array}$ \\
\hline 1 & Ringan & 2 & $7,1 \%$ \\
\hline 2 & Sedang & 1 & $3,6 \%$ \\
\hline 3 & Berat & 16 & $57,1 \%$ \\
\hline 4 & $\begin{array}{l}\text { Sangat } \\
\text { Berat }\end{array}$ & 9 & $32,1 \%$ \\
\hline Jumlah & 28 & $100 \%$ \\
\hline
\end{tabular}

Sumber : Data Primer,Agustus 2017

Berdasarkan

tabel 5.3 menunjukkan bahwa dari 28 responden, didapatkan sebagian besar responden $(57,1 \%)$ mengalami depresi berat.

b. Karakteristik tingkat depresi pada lansia sesudah diberikan terapi musik dzikir.

Tabel 5.4 Distribusi frekuensi responden berdasarkan tingkat depresi pada lansia sesudah diberikan terapi musik dzikir di RT 3 RW 2 Rumah Dinas TNI-AL Pulungan 2017.

\begin{tabular}{llll}
\hline No & $\begin{array}{l}\text { Tingkat } \\
\text { Depresi Pre }\end{array}$ & $\begin{array}{l}\text { Frekuen } \\
\text { si (n) }\end{array}$ & $\begin{array}{l}\text { Persen } \\
\text { tase } \\
(\%)\end{array}$ \\
\hline 1 & Ringan & 14 & $50,0 \%$ \\
\hline 2 & Sedang & 10 & $35,7 \%$ \\
\hline 3 & Berat & 4 & $14,3 \%$ \\
\hline Jumlah & 28 & $100 \%$ \\
\hline
\end{tabular}

Sumber : Data Primer, Agustus 2017

c. Pengaruh terapi musik dzikir terhadap tingkat depresi pada lansia di RT 3 RW 2 Rumah Dinas TNI-AL Pulungan.

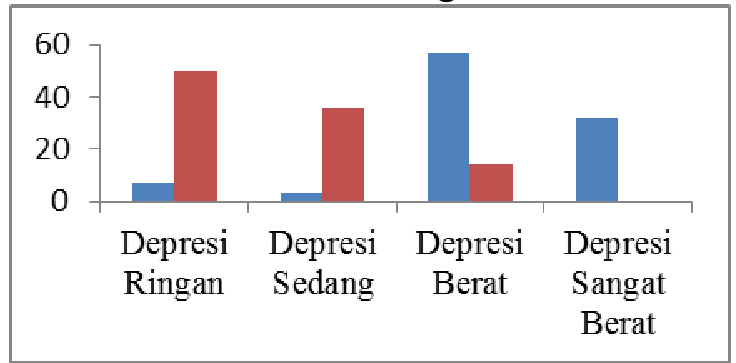

Gambar 5.1 Pengaruh sebelum dan sesudah diberikan terapi musik dzikir terhadap tingkat depresi pada lansia di RT 3 RW 2 Rumah Dinas TNI-AL Pulungan 2017.

Berdasarkan gambar 5.1 menunjukan depresi ringan sebelum diberikan terapi musik dzikir (7,1\%) sesudah diberikan terapi musik dzikir $(50,0 \%)$, depresi sedang sebelum diberikan terapi musik dzikir (3,6\%) sesudah diberikan terapi musik dzikir (35,7\%), depersi berat sebelum diberikan terapi musik dzikir $(57,1 \%)$ sesudah diberikan terapi musik dzikir (14,3\%), dan depresi sangat berat sebelum diberikan terapi musik dzikir (32,1\%) 
sesudah diberikan terapi musik dzikir $(0 \%)$.

\section{Pembahasan}

1. Tingkat depresi pada lansia sebelumdiberikan terapi musik dzikir

Berdasarkan tabel $\quad 5.3$ menunjukkan tingkat depresi pada lansia diRT 3 RW 2 Rumah Dinas TNI-AL Pulungan sebelum diberikan terapi musik dzikir, bahwa dari 28 responden sebagian besar dariresponden $16(57,1 \%)$ responden mengalami depresi berat.

Hal ini dikarenakan kondisi psikis seorang lansia yang lebih banyak beridam diri dirumah, jarang bersosiali sesama tetangga, mempunyai hubungan yang kurang harmonis dengan keluarga ataupun lansia yang bercerai atau berpisah akan lebih merasakan khawatir jika memikirkan masalah, dan seringkali mencemaskan terhadap suatu hal karena tidak mempunyai sesorang untuk bertukar pikiran atau sekedar untuk bererita tentang masalah yang sedang dihadapi. Menurut Maslim, 1997 dikutip Azizah, Lilik 2011 depresi berat yang terjadi dikarenakan kehilangan minat dan kegembiraan, berkurangnya energi yang menuju meningkatnya keadaan mudah lelah (rasa lelah setelah sebentar berkerja), kosentrasi dan perhatian yang kurang, gagasan tentang rasa berasalah dan tidak berguna, pandangan masa depan suram dan pesimis, perbuatan yang membahayakan dirinya sendiri atau bunuh diri, tidur terganggu, disertai waham, halusinasi, lamya gejala tesebut berlangsung 2 minggu.

2. Tingkat depresi pada lansia sesudah diberikan terapi musik dzikir
Berdasarkan tabel $\quad 5.4$ menunjukkan tingkat depresi pada lansia di RT 3 RW 2 Rumah Dinas TNI-AL Pulungan sesudah diberikan terapi musik dzikir, bahwa dari 28 responden setengah dari responden 14 responden $(50,0 \%)$ mengalami depresi ringan.

Hal ini dikarenakan doa dan dzikir mengandung unsur spiritual yang dapat membangkitkan harapan dan rasa percaya diri pada seseorang yang sedang sakit sehingga kekebalan tubuh serta proses penyembuhan dapat meningkatdan memberikan dampak positif bagi tubuh.

Menurut Saudiman, 2011 depresi ringan terjadi sementara, alamiah, adanya rasa sedih dan perubahan proses pikir. Untuk dapat mengatasi keadaan depresi ringan tersebut ada beberapa hal yang dapat dilakukan seperti menciptakan komunikasi terapiutik antara perawat dengan lansia dan menciptakan suasana yang menyenangkan dan menggembirakan. Lanjut usia yang sukses adalah meraka yang aktif dan banyak ikut serta dalam keguatan sosial. Lansia akan merasakan kepuasan bila dapat melakukan aktivitas dan mempertahankan aktivitas tersebut selama mungkin (Darmojo, 2010).

3. Pengaruh terapi musik dzikir terhadap tingkat depresi pada lansia di RT 3 RW 2 Rumah Dinas TNI-AL Pulungan.

Berdasarkan gambar 5.1 didapatkan bahwa sebelum dan sesudah diberikan terapi musik dzikir menunjukkan hampir seluruh responden responden $82 \%$ mengalami penurunan tingkat kecemasan, sebagian kecil dari responden $18 \%$ menunjukkan tidak ada perubahan tingkat depresi sebelum dan sesudah diberikan terapi musik dzikir dan tidak 
ada satupun responden $(0 \%)$ yang mengalami peningkatan tingkat depresi setelah diberikan terapi musik dzikir.

Hal ini dikerenakan respon positif yang diterima dan mengalir keseluruh tubuh yang akan membuat kekebalan imun pada tubuh meningkat.

Berdasarkan penelitian Nurhadi dan Nursalam (2003), bimbingan spiritual berdampak positif terhadap pengurangan stres klien yang dirawat di rumah sakit dan klien dengan penyakit terminal, jika stres dapat dikurangi maka respon imun akan meningkat sehingga infeksi-infeksi sekunder dapat diminimalkan (Setyoadi, 2011).

Peneliti berpendapat terdapat penurunan tingkat depresi lansia sebelum dan sesudah diberikan terapi musik dzikir terjadi karena pertama keadaan psikis responden selama terapi dimana responden mengungkapkan bahwa responden merasa senang dengan terapi yang diberikan oleh peneliti dan menganggap ini hal yang baru sehingga responden menjadi senang dan antusias maka terapi dapat berjalan maksimal dan keadaan rileks bisa tercapai. Kedua adalah semakin lama lansia melakukan terapi maka akan semakin berkurang tingkat depresinya, bisa dikatakan bahwa terapi musik dzikir merupakan meditasi dinamis atau teknik relaksasi yang dinamis dalam waktu singkat. Namun dari 30 responden ada 4responden yang tidak mengalami penurunankecemasan hal ini diduga faktor lingkungan yangmempengaruhi tidak adanya perubahan penurunantingkat depresi. Maksud lingkungan disini yaituresponden tidak menyukai kondisi dimana respondentersebut harus berhubungan atau bersosialisasidengan orang lain pada saat diberikan terapi. Hal inisesuai dengan teori bahwa lingkungan merupakan salah satu penyebab perubahan mental pada lanjut usia, sehingga pada saat di stimulus atau diberikan terapiresponden tersebut tidak dapat fokus dengan apayang telah diberikan dan menyebabkan respondentersebut tidak merasa rileks saat diberikan terapi.

\section{SIMPULAN DAN SARAN}

\section{A. Simpulan}

Berdasarkan penelitian yang telah dilakukan, maka dapat disimpulkan sebagai berikut :

1. Lanjut usia di RT 3 RW 2 Rumah Dinas TNI-AL Pulungansebelum diberikan terapi musik dzikir sebagian besar responden mengalami depresi berat.

2. Lanjut usia di RT 3 RW 2 Rumah Dinas TNI-AL Pulungan sesudah diberikan terapi musik dzikir setengah dari responden mengalami depresi ringan.

3. Terapi musik dzikir berpengaruh terhadap tingkat deprsi pada lanjut usia di RT 3 RW 2 Rumah Dinas TNI-AL Pulungan.

\section{B. Saran}

1. Bagi Peneliti

Diharapkan hasil penelitian ini bisa menambah wawasan dan pengetahuan mengenai pengaruh terapi musik dzikir terhadap tingkat depresi pada lansia di RT 3 RW 2 RumahDinas TNI-AL Pulungan dan dapat dijadikan keterbatasan penelitian sebagai acuan dalam melaksanakan penelitian yang lebih baik kedepannya.

2. Bagi Peneliti lain 
Diharapkan penelitian lebih lanjut dengan metode kualitatif untuk melihat sejauh mana terapi musik dzikir dirasakan efektif dalam meningkatkan kemampuan relaksasi dan dapat dikembangkan dengan meneliti variabel lain yang mungkin berkaitan dengan terapi musik dzikir.

3. Bagi Instansi Pendidikan

Diharapkan bisa sebagai tambahan referensi atau literatur dan pengembangan penelitian tentang pengaruh terapi musik dzikir terhadap tingkat depresi pada lansia, serta digunakan sebagai pedoman untuk melakukan intervensi pada keperawatan lansia.

\section{Bagi Tempat Penelitian}

Diharapkan terapi ini dapat diaplikasikan sebagai salah satu kegiatan di RT 3 RW 2 RumahDinas TNI-AL Pulungan pada lansia sebagai satu bentuk terapi yang menjadi salah satu alternatif untuk mengatasi depresi.

\section{Bagi Responden}

Diharapkan responden dapat melakukan terapi music dzikir secara berulang dan kontinu ketika responden merasa depresi, insomnia, ataupun merasakan terjadinya ketegangan otot.

\section{DAFTAR PUSTAKA}

Anggun, Nurtjahjanti. 2011. Pengaruh Penerapan Tingkat Stress Kerja Pada Pegawai Kereta Api. Jurnal psikologi

Azizah, Lilik Ma'rifatul. 2011. Keperawatan Lanjut Usia. Edisi 1, Yogjakarta, Graha Ilmu

Durmojo, Martono, dkk. 2009. Teori Proses Menua. Jakarta, Balai Penerbit FKUI
Djohan 2006, Terapi Musik Teori dan Aplikasi, Galang Press, Yogyakarta

$$
\begin{aligned}
& \text { Eka, Erwin 2009, Pusat Riset Terapi } \\
& \text { Musik dan Gelombang } \\
& \text { Otak,indonesia, } \\
& \text { http://www.terapimusik/2Desem } \\
& \underline{\text { ber2016.com }}
\end{aligned}
$$

Hidayat, A A 2007, Metode Penelitian Keperawatan dan Teknis Analisa Data, Salemba Medika, Jakarta.

Hardiwinoto, 2005. Panduan Gerontologi Tinjuan dari Beberapa Aspek. Jakarta, PT.Gramedia Pustaka Utama

Hawari, Dadang.2013. Manajemen Stres, Cemas dan Depresi. Cetakan Keempat Edisi II. Jakarta, Fakultas Kedokteran Universitas Indonesia

Ibrahim, Ayub Sani. 2011. Gangguan Alam Perasaan, Manik Deprsi. Edisi I. Tanggerang, Jelajah Nusa

Junaidi, Iskandar. 2012. Anomali Jiwa. Edisi I. Yogjakarta

Kaplan, Sadock dkk. 2010. Sinopsis Psikiatri Ilmu Pengetahuan Perilaku Psikiatri Klinis. Jilid .Editor: Dr. I. Made Wiguna S. Jakarta, Bina Rupa Aksara

Katona,C, Cooper, C., Robertson, M. 2012. At a Glance Psikiatri Edisi Keempat. Jakarta, Erlangga

Natalia, D 2013, Terapi Musik Bidang Keperawatan, Mitra Wacana Media, Jakarta

Nugroho, Wahjudi. 2008. Keperawatan Gerontik \& Geriatrik, Edisi 3. Jakarta, EGC 
Nasir, Abdul \& Muhith, Abdul. 2011. Dasar-dasar Keperawatan Jiwa; Pengantar dan Teori. Jakarta, Salemba Medika

Nursalam, 2013. Konsep Penerapan Metode Penelitian Ilmu Keperaatan. Jakarta, Salemba Medika

Nurmiati, Amir. 2005. Depresi: Aspek Neurobiology, Diagnosis dan Tatalaksana. Jakarta, Balai Penerbit FKUI

Padila. 2013. Buku Ajar Keperawatan Gerontik. Yogjakarta, Nuha Medika

Setyoadi, Kushariyadi. 2011. Terapi Modalitas Keperawatan Pada Klien Psikogeriatik. Jakarta, Salemba Medika

Sugiyono 2013, Metode Penelitian Kuantitatif, Kualitatif dan R \&, Eds19, Alfabeta, Batang 